\title{
Case Report: Hunting Meth Mites by a Cigarette Fire: A Case Study
}

\author{
Mohammad Moshiri $^{1}$ (D, Parastoo Rahimi ${ }^{2}$ (D), Leila Etemad ${ }^{3 *}$ (D) \\ 1. Medical Toxicology Research Center, Mashhad University of Medical Sciences, Mashhad, Iran. \\ 2. Faculty of Veterinary, Islamic Azad University, Science and Research Branch, Tehran, Iran. \\ 3. Pharmaceutical Research Center, Mashhad University of Medical Sciences, Mashhad, Iran.
}

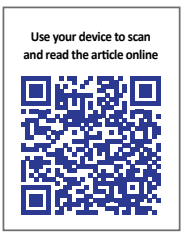

Citation: Moshiri M, Rahimi P, Etemad L. Hunting Meth Mites by a Cigarette Fire: A Case Study. International Journal of Medical Toxicology and Forensic Medicine. 2020; 10(1):25478. https://doi.org/10.32598/ijmtfm.v10i1.25478

doij ${ }^{\circ}$ https://doi.org/10.32598/ijmtfm.v10i1.25478

\section{(c) (i) (5)}

Article info:

Received: 13 May 2019

First Revision: 17 May 2019

Accepted: 27 May 2019

Published: 03 Apr 2020

\section{Keywords:}

Methamphetamine;

Obsessive Behavior; Tactile

Hallucination; Self-harm

\section{ABSTRACT}

Background: Meth mites is a false sense annoys methamphetamine abusers forces them to self-harm by picking the skin, scratching it.

Case Presentation: We reported the photos showed a regular small round skin injuries on the forearms of a middle-age multi-drug abuser man. He explained about his injuries: "I was hunting annoying ants by cigarette fire, however they were fire-resistant and skipped". He had isolated tactile hallucination without visual part. He explained that every time he abuses methamphetamine (Shisheh in Iran) the ants attack him and bite him.

Conclusion: Drug induced formication could be a very dangerous hallucination that forces the patient to self-harm to get rid of it, especially in multidrug abusers.

\section{Introduction}

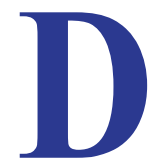

rug abuse induces a sensory hallucination of bugs crawling on or within the skin, especially in the heavy daily users of methamphetamine [1]. Such a condition is called "coke bugs", "meth mites", and "amphetamites". The false sense annoys patients and forces them to self-harm by repetitively picking the skin, scratching it, and so on. The lesions appear in various shapes on different body areas; however, they are more common in easy-to-reach areas and on the opposite side of the patient's dominant hand.

\section{Case Presentation}

The photos (Figure 1) were taken from a middle-aged multidrug abuser male who was admitted to the poisoning ward because of conciseness loss secondary to a drug overdose. On the next morning of admission, he became alert and explained about his forearm's injuries. "I was hunting annoying ants by a cigarette fire; however, they were fire-resistant and skipped". He had isolated tactile hallucination without visual part. He explained that every time he abuses methamphetamine (Shisheh in Persian), the ants attack him and bite him. The studied patient was a multidrug abuser with a positive urine screen

* Corresponding Author:

Leila Etemad, PhD.

Address: Pharmaceutical Research Center, Mashhad University of Medical Sciences, Mashhad, Iran.

Tel: +98 (513) 7112611

E-mail: etemadl@mums.ac.ir 


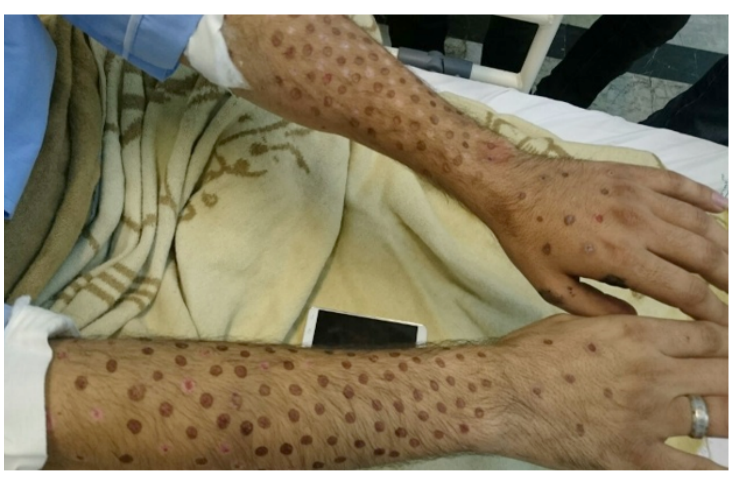

both hands

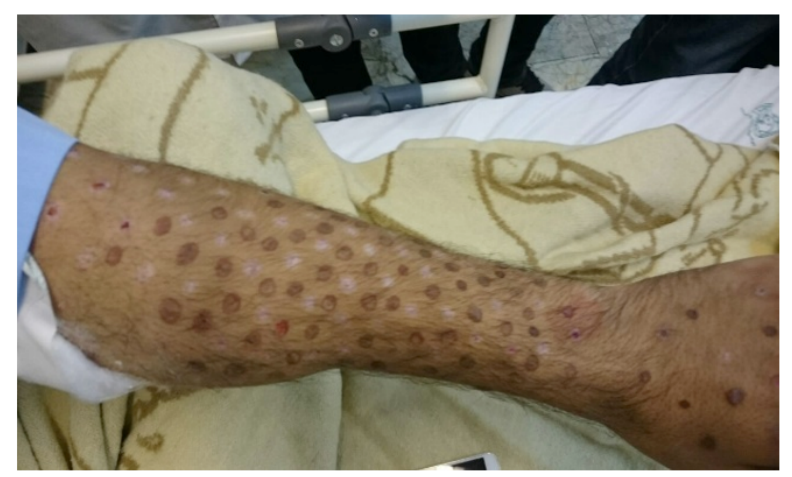

The healed scars of burnt are noticeable.

International Journal of
Medical Toxicology \& Forensic Medicine

Figure 1. Burnt hands by cigarette fire in multi-drug abuser man secondary to drug induced formication.

Left: both hands; Right: left hand; note the healed scars of burnt

test of drug abuse for methamphetamine, amphetamine, morphine, and methadone. He was referred to psychiatric and dermatology departments. Unfortunately, he was discharged with personal consent; therefore, we were not able to proceed further with his case.

Obsessive-compulsive disorder is a prevalent condition in methamphetamine abusers [2]. They become obsessive and attempt to perform compulsive rituals, such as burning imaginary ants by a cigarette lighter. Our studied patient obsessively thought that he should hunt the ant only by a cigarette lighter despite the pain of burnt. The healed scars of burnt on the opposite dominant hand (left hand) demonstrated that the compulsive rituals were repetitive. The studied patient was a multidrug abuser with a positive urine screen test of drug abuse for methamphetamine, amphetamine, morphine, and methadone. We assumed that the mixed-use of methamphetamine and opiate-induced sufficient analgesia, leading him to self-burn [3].

\section{Conclusion}

In conclusion, drug-induced formication could be a highly dangerous hallucination; consequently, it forces the patient to self-harm to stop it, especially in multidrug abusers.

\section{Ethical Considerations}

\section{Compliance with ethical guidelines}

The patient let us to publish his forearms photos by signing the informed consent form.

\section{Funding}

This research did not receive any specific grant from funding agencies in the public, commercial, or not-forprofit sectors.

\section{Author's contributions}

Visiting the patient, taking photos, writing the first draft: Mohammad Moshiri; Translating and editing the manuscript: Parastoo Rahimi; Corresponding and approving the final draft: Leila Etemad.

\section{Conflict of interest}

The authors declared no conflicts of interest.

\section{Acknowledgements}

We would like to thank the staff of poisoning ward of Imam Reza Hospital for their kind cooperation.

\section{References:}

[1] Rusyniak DE. Neurologic manifestations of chronic methamphetamine abuse. The Psychiatric clinics of North America. 2013; 36(2):261-75. [DOI:10.1016/j.psc.2013.02.005] [PMID] [PMCID]

[2] Eslami-Shahrbabaki M, Fekrat A, Mazhari S. A study of the prevalence of psychiatric disorders in patients with methamphetamine-induced psychosis. Addiction \& Health. 2015; 7(1-2):37-46. [PMID] [PMCID]

[3] Sasson S, Unterwald EM, Kornetsky C. Potentiation of morphine analgesia by d-amphetamine. Psychopharmacology (Berl). 1986; 90(2):163-5. [DOI:10.1007/BF00181233] [PMID] 